\title{
Generically Free Choice
}

\section{Citation}

Nickel, Bernhard. 2010. “Generically Free Choice." Linguistics and Philosophy 33 (6) (December): 479-512. doi:10.1007/s10988-011-9087-4.

\section{Published Version}

doi:10.1007/s10988-011-9087-4

\section{Permanent link}

http://nrs.harvard.edu/urn-3:HUL.InstRepos:34565390

\section{Terms of Use}

This article was downloaded from Harvard University's DASH repository, and is made available under the terms and conditions applicable to Open Access Policy Articles, as set forth at http:// nrs.harvard.edu/urn-3:HUL.InstRepos:dash.current.terms-of-use\#OAP

\section{Share Your Story}

The Harvard community has made this article openly available.

Please share how this access benefits you. Submit a story.

Accessibility 


\title{
Generically Free Choice*
}

\author{
Bernhard Nickel · Department of Philosophy \\ Harvard University
}

January 13, 2011

\begin{abstract}
This paper discusses free-choice like effects in generics. Just as Jane may drink coffee or tea can be used to convey Jane may drink coffee and Jane may drink tea (she is "free to choose"), some generics with disjunctive predicates can be used to convey conjunctions of simpler generics: elephants live in Africa or Asia can be used to convey elephants live in Africa and elephants live in Asia. Investigating these logically slightly more complex generics and especially the free-choice like effects throws light on both the semantics of generics and the interaction between world knowledge and the interpretive options generics offer. This paper presents a package of semantic and pragmatic hypotheses to account for the data, including why the effect is absent in the superficially logically similar elephants live in Africa or give birth to live young.
\end{abstract}

\section{Keywords SEMANTICS · NATURAL LANGUAGE - GENERICS · PLURALS - FREE CHOICE $\cdot$ DISTRIBUTIVITY}

\section{Introduction}

As is well known, disjunctions often convey the denials of corresponding conjunctions. But as Kamp [1973] pointed out, disjunctions surprisingly enough sometimes also convey conjunctions. The paradigm is given in (1), where ' $\rightsquigarrow$ ' indicates that information is conveyed.

(1) Jane may have coffee or tea.

a. $\rightsquigarrow$ Jane may have coffee.

b. $\rightsquigarrow$ Jane may have tea.

*I presented ancestors of this paper at the 2007 APA Pacific Division meeting, where Agustin Rayo gave me helpful comments, as well as at the Australian National University. Some of this material was also presented at the University of Stockholm, the Arché Research Center at the University of St. Andrews, and the GENIUS research group on generics in Paris. Thanks to all discussants for their help in improving this paper. In its final revision, this paper benefitted greatly from the comments of an anonymous referee for this journal. 
When (1) is asserted by a speaker with the authority to actually give the relevant permission, it usually conveys the conjunction of (1a) and (1b), though it does not convey that Jane may have both. ${ }^{1}$ Because this amounts to saying that Jane has permission to freely choose between the two options, this phenomenon is usually called free choice permission. Note that free choice permission requires that the disjunction is phrasal. Asserting the clausal disjunction of (1a) and (1b), Jane may have coffee or Jane may have tea does not convey such freedom of choice.

I said that these sentences naturally convey the conjunction of individual permissions because there are also situations in which the phenomenon is absent, most notably situations in which a speaker is giving voice to her ignorance. Imagine that (1) is said not by a person with the authority to grant the permission, but by someone who merely knows that one of the two permissions (1a) and (1b) was given without knowing which. In that situation, (1) conveys only the disjunction of (1a) and (1b).

The present paper is concerned with a similar paradigm involving not permissions but generics. My discussion will revolve around the data in (2).

(2) Elephants live in Africa or Asia.
a. $\rightsquigarrow$ Elephants live in Africa.
b. $\rightsquigarrow$ Elephants live in Asia.

Just as (1) can naturally convey the conjunction of (1a) and (1b), (2) can naturally convey the conjunction of (2a) and (2b). Some further examples of the same paradigm. ${ }^{2,3}$

(3) Cactus flowers are red, white, or yellow.
a. $\rightsquigarrow$ Cactus flowers are red.
b. $\rightsquigarrow$ Cactus flowers are white.
c. $\rightsquigarrow$ Cactus flowers are yellow.

(4) EE cats (i.e., cats with a certain genetic marker) are black or tabby.
a. $\rightsquigarrow$ EE cats are black.
b. $\rightsquigarrow$ EE cats are tabby.

\footnotetext{
${ }^{1}$ This is an instance of the general point that from the fact that it is permitted that $p$ and that it is permitted that $q$, it doesn't follow that it is permitted that $p$ and $q$.

${ }^{2}(3)$ is taken from Britannica-online (http://www.britannica.com/EBchecked/topic/333776/leafcactus). (4) comes from Little [1958, 121].

${ }^{3}$ There's another proposition that is conveyed by this kind of disjunction, roughly that Africa and Asia are the only natural habitats for elephants. I take it that this is an implicature, rather than part of the semantics of the sentence, since it can be cancelled: bears live in Europe or Asia, though I don't mean to suggest that these are their only habitats..
} 
Since we aren't dealing with permissions or choice, I'll call this phenomenon conjunctive strengthening, though the features I just pointed out for permission do carry over to generics. Just as in the case of permissions, the disjunction in the verb-phrase (VP) gives rise to a clausal conjunction, and we cannot validly infer from the clausal conjunction to a phrasal conjunction, e.g., we cannot infer from (3a)-(3c) that cactus flowers are red, white, and yellow in the sense that individual flowers are all three colors. And conjunctive strengthening is present only when the disjunction is in the VP. Asserting the disjunction of (2a) and (2b), elephants live in Africa or elephants live in Asia does not convey their conjunction.

Accounting for conjunctively strengthened generics turns out to be a useful arena for investigating the semantics of generics quite generally. The fact that the phenomenon is present in generics at all argues for a very specific semantic theory, since most current theories would predict that generics do not give rise to conjunctive strengthening. The phenomenon also allows us to investigate how world knowledge enters into the interpretation of generics. Specifically, I will be concerned to account for contrasts such as the one between (2) and (5).

(5) Elephants live in Africa or give birth to live young.

a. $\not \hookrightarrow$ Elephants live in Africa.

b. $\Varangle$ Elephants give birth to live young.

Clearly, (5) is very odd, and that is due to the fact that conjunctive strengthening isn't generally available for it (I'll explain this qualification in $\S 4$ ). Without conjunctive strengthening, we can only understand (5) as a simple disjunction, and it is extremely hard for us to imagine how someone could have gotten herself into a state of ignorance where she knows that one of $(5 \mathrm{a})$ and $(5 \mathrm{~b})$ is true without knowing which one. That the unavailability of conjunctive strengthening, rather than the fact that (5) is a disjunction with two true disjuncts, is really the basic culprit in the oddity of (5) can be seen from the fact that we know both disjuncts of (2) to be true, as well, and yet (2) is perfect. That's just because in (2), we can strengthen the disjunction conjunctively, something we can't do in (5). Since the two sentences are logically isomorphic, there must be some other factor that accounts for the difference between these, and I'll argue that this other factor shows the logical form (LF) of generics to be richly articulated.

A caveat before we begin. Each of the components I will appeal to in order to account for the data represents a substantive hypothesis. I'll motivate these components and explain why I accept them rather than some alternatives, but I cannot defend each of them fully. I hope that showing these hypotheses to work together to account for the data I discuss in this paper will serve to provide some additional support. 


\section{Semantics for Generics}

That generics exhibit conjunctive strengthening at all is surprising, considering some basic features of most of the semantic theories for generics currently in the literature. Some of these theories analyze all generics as kind predications, so that elephants live in Africa has a simple subject-predicate structure $F a$, in this case roughly that the kind elephant has the feature of living in Africa. ${ }^{4}$ The remaining accounts introduce a generic operator into the logical form (LF) of generics, and the semantics of that operator are roughly a suitably restricted universal quantifier or most, ranging over a suitably constrained domain [see, inter alia, Asher and Morreau, 1995, Cohen, 1999a,b, Eckardt, 1999, Greenberg, 2007]. ${ }^{5}$ However, if we look at the constructions that allow for conjunctive strengthening, we find that neither simple subject-predicate constructions (6) nor universally quantified or majority claims (7) give rise to it, while existentially quantified sentences do (8). ${ }^{6}$

(6) (The train was very stuffy.) Jane had trouble breathing or felt nauseous. \& $\rightarrow$ Jane had trouble breathing and felt nauseous.

(7) a. (The train was very stuffy.) All passengers had trouble breathing or felt nauseous.

\& $\rightarrow$ All passengers had trouble breathing and all passengers felt nauseous.

b. (The train was very stuffy.) Most passengers had trouble breathing or felt nauseous.

$\Varangle \rightarrow$ Most passengers had trouble breathing and most passengers felt nauseous.

(8) a. (The train was very stuffy.) Some passengers had trouble breathing or felt nauseous.

$\rightsquigarrow$ Some passengers had trouble breathing.

$\rightsquigarrow$ Some passengers felt nauseous.

b. (This course is very hard.) Some students take three semesters to complete it or do not finish it at all.

$\rightsquigarrow$ Some students take three semesters to complete the course.

$\rightsquigarrow$ Some students do not finish the course at all.

Thus, the basic semantics most accounts of generics give suggest that generics should pattern with universal generalizations or simple predications. None of them should give rise to conjunctive strengthening. I will take this fact as motivation for an alternative semantics for generics on which their logical structure is more closely akin to existentials. But I'll consider a likely source of concern first.

\footnotetext{
${ }^{4}$ See Carlson [1977], Liebesman [2010].

${ }^{5} \mathrm{By}$ LF, I mean a syntactically (and psychologically) real representation of the sentence that determines the interpretation of that sentence. See, e.g., Sag [1976].

${ }^{6}$ The observations in (8) are due to Fox [2007], Klinedinst [2007].
} 


\subsection{Mere Existentials?}

Since the semantics I present here go against a large number of other theories, I first want to consider a proposal that retains the basic idea of modeling generics roughly on universally quantified claims and on which generics are predicted to convey systematically related conjunctions. The basic observation is that generally, universally quantified sentence with disjunctive predicates give rise to an implicature that each of the predicates forming the disjunction is satisfied by something in the domain. In many ordinary contexts, (9) suggests both (9a) and $(9 \mathrm{~b})$.

(9) All of the students are girls or boys (none are adults).
a. $\rightsquigarrow$ Some students are girls.
b. $\rightsquigarrow$ Some students are boys.

Likewise, one might maintain that (2) suggests that both (10a) and (10b) are true.

(10) a. There are elephants in Africa.

b. There are elephants in Asia.

Thus, the appearance of conjunctive strengthening in (2) is really just an implication that two existential claims are true, and hence the bare plurals in (2a) and $(2 \mathrm{~b})$ should be interpreted as existential bare plurals, not genuine generics in their own right.

There are three concerns about this alternative proposal. The first is that it overpredicts conjunctive strengthening, since on this alternative proposal, all there is to its appearance is the presence of implicated existential claims, and these should likewise be present in (5). Yet conjunctive strengthening is unattested there.

Second, the truth of an existential sentence is insufficient to verify the proposition conveyed when conjunctive strengthening is present. In addition to (10a) and (10b), (11) is also true.

(11) There are elephants in Europe.

We should thus expect that (12) also conveys a truth when it is conjunctively strengthened, since on the present proposal, the propositions it conveys are purely existential.

(12) Elephants live in Africa, Asia, or Europe.

However, (12) is clearly unacceptable when it is understood as conjunctively strengthened, an understanding that can be brought to the fore by continuing (12) with ... each is equally natural.

Finally, consider generics about properties that could happen to not be instantiated in a population for a while before resurfacing, such as having green 
eyes. The conjunctive strengthening of (13a) conveys each of (13b)-(13d), and these are clearly true, even if there happen not to be any green-eyed people at a given point in time.

(13) a. Humans have blue, brown, or green eyes.

b. Humans have blue eyes.

c. Humans have brown eyes.

d. Humans have green eyes.

This speaks strongly in favor of analyzing the conveyed propositions in cases of conjunctively strengthened generics as genuine generics, not mere existentials, since genuine generics can be true even when there happen not to be any members of the kind that conform to them at a given point of evaluation, whereas existentials cannot (cf. ravens are on my lawn said at a time when my lawn is devoid of ravens).

\subsection{Ways of Being Normal}

We therefore need some account of the semantics of generics on which we can predict that they allow for a conjunctive strengthening, and where the propositions conveyed are genuine generics. I want to motivate just such a semantics now on grounds that are independent of the phenomenon of conjunctive strengthening in generics. I'll reverse-engineer them from the two generics that we want to predict are conveyed by $(2),(2 \mathrm{a})$ and $(2 \mathrm{~b})$, repeated here. ${ }^{7}$

(2) a. Elephants live in Africa.

b. Elephants live in Asia.

That both of these can be true is puzzling in itself. To see the puzzle, assume that we paraphrase generics of the form $A s$ are $F$ as restricted universal quantification over the normal members of the kind, i.e., as all normal As are F. In that case, (2a) and (2b) would be equivalent to (14a) and (14b), respectively, and these should jointly entail (14c).
a. All normal elephants live in Africa.
b. All normal elephants live in Asia.
c. All normal elephants live in (both) Africa and Asia.

But (14c) is obviously false, and hence the paraphrase in terms of (14a) and (14b) must have been mistaken, as well, since the original (2a) and (2b) do not imply that any elephants live on more than one continent. ${ }^{8}$

Now, it is well known that flatfooted normality analyses of generics fail quite independently of examples like (2a) and (2b). Examples such as (15a) have been familiar in the literature at least since Carlson [1977].

\footnotetext{
${ }^{7}$ The discussion here follows the more detailed arguments in Nickel [2008].

${ }^{8} \mathrm{~A}$ very closely related problem arises if we paraphrase generics in terms of most following Cohen [1999b]. In that case, $(2 \mathrm{a})$ and $(2 \mathrm{~b})$ are equivalent to most elephants (in the suitable domain) live in Africa and most elephants (in the suitable domain) live in Asia, which entails
} 

a. Chickens lay eggs.
b. All normal chickens lay eggs.
c. Necessarily, all chickens that lay eggs are hens.
d. All normal chickens are hens.
e. Chickens are hens.

The flatfooted analysis interprets (15a) as (15b), which together with (15c) entails (15d). But that is just what we'd expect the analysis of (15e) to be, so that the simple normality analysis is committed to treating (15a) as entailing (15e).

This is a problem for all quantificational accounts of generics, accounts that want to give an informative analysis of $A s$ are $F$ in terms of the distribution of the property of being an $F$ among the actual and possible As. And the most common way of resolving this problem is by restricting the quantifier as a function of the predicate at issue in the generic. In the framework of quantification over normal members of a kind, we might capture this idea by considering not the members of the kind that are normal, simpliciter, but those that are normal in a certain respect, where that respect is determined by the predicate.

Such a respect is a determinable of the property expressed by the predicate, a way of having that property. For example, if the predicate is black, the respect of normality is color, if the predicate is striped, the respect is pattern, and so on. In some cases, there may be a small number of determinables that a given property expressed by the predicate could be a determinate of. (16) illustrates this possibility.

(16) Bears ride unicycles.

There are at least two determinables of the property of riding a unicycle: means of locomotion and tricks performed in a circus. If the former determinable is at issue, i.e., if we're interpreting (16) as about bears that are normal with respect to their means of locomotion, it is clearly false. If the latter is at issue so that we're interpreting (16) as about bears that are normal with respect to the tricks they perform at circuses, it may well be true. When there are such multiple determinables, the context has to select one. ${ }^{9}$

Taking account of respects of normality, the two generics (15a) and (15e) are analyzed as in (17) and (19), respectively.

that some elephants live on both continents. I won't discuss how the dialectic in the main text plays out with respect to Cohen's view. For such a discussion, see Nickel [2008].

On a kind-predication view, the problem doesn't arise in the same way because the hallmark of this strategy is precisely that there aren't any hard and fast logical or semantic implications connecting generics and claims about the properties of particular members of a kind. Thus, a kind-predication theorist isn't committed by the truth of (2) to any claims about the habitats of individual elephants. However, I do not consider the kind-predication strategy further here because of the many objections it faces in the literature.

${ }^{9}$ The issue of the availability of determinables in context will arise again in $\S 4.2$, when I discuss the conditions that must be satisfied in order for a generic to allow conjunctive strengthening. 
(17) All chickens that are normal with respect to how chickens extrude offspring lay eggs.

(18) All chickens that are normal with respect to how chickens extrude offspring are hens.

(19) All chickens that are normal with respect to the sex of chickens are hens.

These analyses effectively block the inference from (15a) to (15e). Even with the additional premise (15c), all we are entitled to conclude is (18), which is indeed true, but which does not entail (19). Moreover, (19) is false, so that we can also predict the attested truth-value judgment for the original chickens are hens. ${ }^{10}$

But this way of resolving the problem posed by chickens and their reproduction cannot be extended to deal with the fact that (2a) and (2b) can both be true without entailing that there are any elephants that live in both Africa and Asia because plausibly, the same respect of normality is determined by both of the predicates involved - being normal with respect to habitat.

Following the argument in Nickel [2008], I want to suggest that we interpret $(2 \mathrm{a})$ and $(2 \mathrm{~b})$ in terms of ways of being normal (in a given respect), i.e., by introducing another parameter into the interpretation of normality, beyond relativizing it to respects. A way into this idea is to sketch a bit of an analysis of normality. Begin with the hypothesis that we interpret generics basically in terms of causal mechanisms. On this approach, the reason that ravens are black is true is that there is a stable causal mechanism of the right kind that causes blackness in ravens. ${ }^{11}$ The reason that ravens are white is false is that, although there are some white ravens and there may even be a stable causal mechanism that makes this so, that mechanism isn't of the right kind to underwrite the generic. Saying what makes a mechanism "of the right kind" with any degree of generality is a very hard problem, but in this paper, I want to proceed by relying on the intuitive grip we have on the notion. ${ }^{12}$

\footnotetext{
${ }^{10}$ The basic problem and solution I mention in the text are very general. An implementation that is most similar to my own is given by Ariel Cohen. On his view, the generic quantifier is restricted by a set of alternatives provided by the predicate [see Cohen, 1999a,b, 2004]. But even within different semantic frameworks, the same dialectic unfolds. In the case of situation semantics [Barwise, 1986, Gerstner-Link, 1988, Parwise and Perry, 1983, ter Meulen, 1986] suggest using constraints on situations to restrict the range of situations relevant to the evaluation of generics. Within the framework of default inferences, circumscription plays the same role [see McCarthy, 1980, 1986].

${ }^{11}$ Clearly, connecting generics to causal mechanisms in the way I am sketching is an instance of what Carlson [1995] calls the rules-and-regulations approach to the semantics of generics, and stated at this level of generality, it faces many of the problems Carlson mentions. To pick just one, we don't want to interpret generic comparisons such as cows are heavier than ravens in terms of a rule or mechanism dedicated to bringing about the relevant comparative fact. Whether this is ultimately problematic depends on how the connection between the truth-conditions of generics is forged through the compositional semantics of these sentences. For a semantics that does not require relational mechanisms to interpret comparisons, see Nickel [2010b].

${ }^{12}$ Some reason to think that we have such a grip: if we try to imagine exceptions to a generic we accept (such as non-black ravens for ravens are black, we very naturally think in terms
} 
If we think of the truth of at least these simple generics as closely connected to the existence of causal mechanisms like this, a feature of the generics that are most often discussed is revealed as merely contingent. In the case of ravens are black, any sentence we obtain by replacing black with another color yields a falsehood. Likewise, replacing striped in tigers are striped with any other pattern yields a falsehood. More generally, very many true generics are such that, if we replace the predicate with one that picks out another determinate of the determinable that picks out the respect of normality at issue, we go from a truth to a falsehood. Based on examples like the ones I just mentioned, one might think that (20) is a consequence of the semantics of generics.

(20) If a generic As are $F$ is true, interpreted with respect of normality $\operatorname{DET}_{F}$ and $G$ is a different predicate that picks out a property that is also a determinate of $\operatorname{DET}_{F}$, then As are $G$ is false.

Examples like (2a) and (2b) about the habitat of elephants or similar ones about the color of flowers shows that (20) is in fact false, let alone a constraint to be derived from the semantics of generics. That the instances of (20) for ravens are black and tigers have stripes are true is rather a contingent fact about ravens and tigers. Thinking about the semantics in terms of mechanisms makes it easy to see why that should be. For definiteness, we can think about the coloration mechanisms that are present in a population as a result of natural selection. Selection might account for just a single such mechanism, as in the case of ravens, but it need not, as in the case of cactus flowers that are selected for their ability to attract insects. And what goes for coloration goes for other features, such as components of diet, body shape, and habitat.

In order to make the semantics of generics sufficiently flexible to allow for these possibilities of multiple, equally normal colors, habitats, body shapes, or what-have-you, I suggest that we existentially quantify over ways of being normal in a given respect, where the existence of such a way of being normal is underwritten by the existence of a corresponding mechanism of the right kind. It is precisely for this reason that I want to distinguish the two ingredients in the notion of normality used in interpreting generics, a respect of normality and ways of being normal in that respect. At least in context, a generic is always interpreted in terms of a single respect of normality. But for many kinds and respects, there are multiple ways of being normal, as in the case of coloration for flowers.

For the specific examples of (2a) and (2b)-repeated here as (21a) and (22a) - we thus obtain the following interpretations.

a. Elephants live in Africa.

b. There is a way of being an elephant that is normal with respect to its habitat, and all elephants that are normal in that way live in Africa.

of derailing a corresponding mechanism. Theoretically, it's a significant challenge to say at the appropriate level of generality what makes a mechanism a mechanism of the right kind to underwrite a generic. For a sketch of such a theory, see Nickel [2010a]. 
a. Elephants live in Asia.

b. There is a way of being an elephant that is normal with respect to its habitat, and all elephants that are normal in that way live in Asia.

Put in terms of mechanisms, (21b) and (22b) together assert that there are distinct causal mechanisms, one of which sustains the population of African elephants and the other of which sustains the population of Asian elephants.

These semantics immediately make the prediction that (21a) $[=(2 \mathrm{a})]$ and (22a) $[=(2 \mathrm{~b})]$ can both be true without implying that there are any individual elephants that have multiple habitats, since the quantifiers are restricted to disjoint domains. To put this proposal more formally, I'll assume the preliminary representation of a generic sentence with bare plural subject $A$ and predicate $F$ in (23). (24) gives an example.

(23) $\operatorname{Gen}(A s ; F)$
a. Ravens are black.
b. Gen(Ravens; black)

This proposal doesn't yet say anything about the LF of generics, specifically about where the generic operator originates and whether it is an adverb of quantification, a nominal determiner, or something else (I'll return to this point in $§ 4.1)$. (23) is simply a bit of regimentation to ease exposition. The general semantic proposal is this.

\section{Semantics for Generics}

(25) $\operatorname{Gen}(A s ; F)$ is true iff

$[\exists N$ : Way.Of.Being.F-normal.A $(N)][\forall x: A(x) \wedge N(x)](F(x))$.

In this proposal, I'm abbreviating the notion of being normal with respect to a feature determined by the predicate $F$ as $F$-normal. In words, (25) says that As are $F$ is true iff there is a way of being an $F$-normal $A$, and all $A$ s that are normal in this way are $F$.

This sketch of the semantics goes some way towards accounting for the conjunctive strengthening of generics like (2). The straightforwardly existential claims (8a) and (8b) showed that an existential with a disjunctive predicate can convey the conjunction of existentials with each of the disjuncts. Given the semantics I just sketched, generics with disjunctive predicates have an analogous logical structure. This is most obvious if we consider the logical representation of (8a) and its conjunctive strengthening alongside the semi-formal translation of (2) and its strengthening.

(26) Some passengers were nauseous or had trouble breathing.

a. $[\exists x$ : Passenger $(x)](\operatorname{Nauseous}(x) \vee$ Had.Trouble.Breathing $(x))$

b. $[\exists x$ : Passenger $(x)]($ Nauseous $(x))$ 
c. $[\exists x$ : Passenger $(x)]($ Had.Trouble.Breathing $(x))$

(27) Elephants live in Africa or Asia.

a. $[\exists N$ : Way.Of.Being.F-normal.Elephant $(N)]$ $[\forall x$ : Elephant $(x) \wedge N(x)]$ (Live.in.Africa $(x) \vee \operatorname{Live.in.Asia~}(x))$

b. $[\exists N$ : Way.Of.Being.F-normal.Elephant $(N)]$

$$
[\forall x: \text { Elephant }(x) \wedge N(x)](\text { Live.in.Africa }(x))
$$

c. $[\exists N$ : Way.Of.Being.F-normal.Elephant $(N)]$

$$
[\forall x \text { : Elephant }(x) \wedge N(x)](\text { Live.in.Asia }(x))
$$

Let me now consider some further aspects of these semantics that are relevant to the present topic before turning to the account of conjunctive strengthening that I adopt.

\subsection{Homogeneity}

Making the semantics more flexible by existentially quantifying over ways of being normal has its costs, since the change in logical structure brings with it changes in inferential behavior. Consider the following argument, which is intuitively valid.

(i) Elephants live in Africa or Asia.

(ii) Elephants don't live in Africa.

$\therefore$ (iii) Elephants live in Asia.

This inference is particularly important in the present context because the account of conjunctive strengthening I'll propose below (§3) relies on it. Unfortunately, the present semantics predict that the argument is invalid. To see this, consider the semi-formal translation of these premises.

(i') $[\exists N$ : Way.Of.Being.Habitat-normal.Elephant $(N)]$

$[\forall x$ : Elephant $(x) \wedge N(x)]($ Live.in.Africa $(x) \vee \operatorname{Live.in.Asia~}(x))$

(ii') $\neg[\exists N$ : Way.Of.Being.Habitat-normal.Elephant $(N)]$

$$
[\forall x: \text { Elephant }(x) \wedge N(x)](\text { Live.in.Africa }(x))
$$

$\therefore$ (iii') $[\exists N$ : Way.Of.Being.Habitat-normal.Elephant $(N)]$

$$
[\forall x: \text { Elephant }(x) \wedge N(x)](\text { Live.in.Asia }(x))
$$

Informally, the problem is this. (ii') says that there's no way to have a normal habitat such that all elephants that are normal in that way live in Africa. But even if not every elephant that's normal in that way lives in Africa, some elephants might for all that (ii') says. In that case, we have a "mixed" way of being 
normal, so that some elephants that are normal in that way live in Africa, some in Asia. If those are the only places that elephants that are normal in that way live, the first premise is verified as well, but the conclusion could be false.

Intuitively, of course, these kinds of possibilities seem to be completely irrelevant to our assessment of the initial argument (i)-(iii) as valid. ${ }^{13}$ An informal way of stating a principle that would capture our judgments of validity is the following: once we've ruled out Africa as the habitat for some elephants that are normal in a particular way $w$, we've ruled it out for all of them. Therefore, if we can infer that for any given way of being normal with respect to their habitat, some elephants that are normal in that way don't live in Africa, we can conclude that no normal elephants live in Africa. I propose that we introduce a principle that generalizes this idea as part of the semantics of generics.

I'll call this principle HOMOgEnEITY. Suppose we're considering a kind, the $A \mathrm{~s}$, and a property $F$ that we might predicate of the $A \mathrm{~s}$ in a generic sentence. In that case, we can infer from the fact that at least some $A$ s that are normal in the relevant respect aren't $F$ to the conclusion that no $A$ s that are normal in that respect are $F$. Formally:

\section{homogeneity}

$[Q N] \neg[\forall x: F x \wedge N x](G x) \vdash[Q N][\forall x: F x \wedge N x](\neg G x)$,

where $Q$ is $\forall$ or $\exists$.

HOMOGENEITY, if accepted, rules out precisely the kinds of possibilities that threatened to make the inference $\left(\mathrm{i}^{\prime}\right)$-(iii') invalid. The results of this addition are exhibited in (28), where (i) and (ii) are rendered as (28a) and (28b), respectively.

$$
\begin{aligned}
& \text { a. }[\exists N][\forall x \text { : Elephant }(x) \wedge N(x)](\text { Live-In-Africa }(x) \vee \operatorname{Live-In-Asia}(x)) \\
& \text { b. } \neg[\exists N][\forall x \text { : Elephant }(x) \wedge N(x)](\text { Live-In-Africa }(x)) \\
& \text { c. }[\forall N][\forall x \text { : Elephant }(x) \wedge N(x)] \neg(\text { Live-In-Africa }(x)) \\
& \text { d. }[\exists N][\forall x \text { : Elephant }(x) \wedge N(x)](\operatorname{Live-In-Asia~}(x))
\end{aligned}
$$

Given Homogeneity, (28b) entails (28c), which together with (28a) does entail (28d). And (28d) is the representation of (iii), so that we can now predict the attested validity of the inference from (i) and (ii) to (iii).

The central question is whether we can give some independent justification for HOMOGENEITY. Being forced to introduce such a principle by brute force is a strike against a semantic theory that requires it, so I want to see whether it can be motivated in a more principled way.

\footnotetext{
${ }^{13}$ This is just a version of the point Carlson [1977] made in arguing against quantificational analyses of generics. Generally, to assert an un-negated generic seems to say something about suitably many members of a kind. But to deny a generic isn't just to assert that most members conform to the generic, but rather that pretty much none do. Consider the contrast between ravens are black and ravens aren't black, for example. The latter isn't just the negation of all normal ravens are black, since the negation isn't compatible with some normal ravens being black.
} 
One strategy for giving such principled motivation looks to general constraints governing the interpretation of plurals. To that end, Fodor [1970] [cited also by von Fintel, 1997] suggests that HOMOGENEITY is a general feature of plurals, not just bare ones. For example, plural definite descriptions such as the children are supposed to come with an "all-or-nothing" presupposition, the presupposition that the predicate applies to all the things denoted by the description or to none. ${ }^{14}$ This proposal receives prima facie support from the observation that saying that it is false that the children are asleep is usually tantamount to saying that none of them are. However, as Brisson [2003] has argued, many perfectly acceptable plurals seem to fail the proposed presupposition and are no worse for the wear. For example, it may be true that the students asked questions after class, even though only a minority of the students actually said anything. ${ }^{15}$ Thus, we should see whether we can find another motivation for the HOMOGENEITY assumption.

We can do so specifically for the case of generics by returning to the role of mechanisms in their interpretation. Above, I suggested that a member of a kind is normal in some respect and in a given way just in case it is involved in a corresponding mechanism. A raven is normally colored iff it develops its color via a certain developmental mechanism, for example. If we link the interpretation of generics to mechanisms in this way, HOMOGENEITY amounts to a constraint on mechanisms. HOMOGENEITY is true iff the mechanisms are individuated at least in part in terms of their endpoints. Let me explain that connection and then use it to motivate HOMOGENEITY.

Suppose that a raven is normally colored in a certain way just in case it goes through a particular developmental process. What does it actually take for the condition to be satisfied, i.e., what does it take for the process a given raven goes through to be an instance of the one that certifies ravens as normally colored? To answer that question, we specify certain benchmark events. If the particular raven's development includes the benchmarks, the raven counts as normally colored; if not, not. It's clear enough what some of these benchmarks are, such as being born with a standard genetic endowment, rather than one for albinism. Is ending up with black feathers one of the benchmark events that help to individuate the process? If it is, it's impossible to be a normally colored raven in the way that corresponds to this mechanism and not be black.

Now the connection between individuating mechanisms in terms of their endpoints and HOMOGENEITY. Suppose that mechanisms are individuated in terms of their endpoints. If there is a raven (say) that is normally colored in some way $w$ and not black, that entails that being a raven that is normally colored in that way is sufficient for being some color other than black, and hence that all normally colored ravens are some other color than black. HOMOGENEITY follows. Suppose that mechanisms aren't individuated in terms of their endpoints. In

\footnotetext{
${ }^{14}$ See von Fintel [1997, 33], citing Fodor [1970, 159-67].

${ }^{15} \mathrm{I}$ 'm not sure how compelling this argument is. It may be the case that the students asked questions after class exhibits a "team-credit" phenomenon, which is paradigmatically shown by The Brazilians scored the prettiest goal of the tournament, which may well be true even though only one Brazilian player actually put the ball in the net.
} 
that case, it's possible for (say) a raven that is normally colored in some way $w$ to be black but it's also possible that such a raven is not black. Because both are possibilities, HOMOGENEITY fails.

So why think that the relevant mechanisms are individuated at least in part in terms of their endpoints? Accepting that they are allows us to dissolve what is an otherwise puzzling phenomenon. On the one hand, generics such as ravens are black are obviously contingent. On the other hand, it is extremely difficult to imagine a raven that isn't black but that nonetheless strikes us as normal, rather than just another exception that the generic can tolerate. This is surprising, because to say that the generalization that ravens are black is contingent would seem to mean that it's possible for there to be counterexamples, and yet we can't imagine any. To imagine a world that is accurately described as one in which ravens aren't black, we need to imagine one that is quite different. So different, in fact, that none of the black ravens in that world strike us as normal anymore.

We can dissolve the puzzle by accepting that the mechanisms that define normality are individuated at least in part in terms of their endpoints - that accounts for our inability to imagine normally colored non-black ravens - but that it is contingent which developmental mechanisms certify a raven as normally colored. However, for that to change requires large scale changes, and once what is normal has changed, nne of the things that used to be normal are normal anymore. Blackness in ravens has quite generally become an aberration. ${ }^{16}$

\subsection{Too Many True Generics?}

Once I introduce different ways of being normal, one might also worry that the semantics become too weak: they predict that too many generics are true. Informally, the worry can be presented like this. If it's possible for several generics that all concern the same respect of normality to be true, are there any limits on how finely we can discriminate ways of being normal? For example, it looks as if we can discriminate between two ways for elephants to be normal with respect to their habitat, living in Africa and living in Asia. But why not discriminate further? Given that all of the elephants that live in Afica must live in some African country, why not think that there are more ways of being normal in this respect: living in (say) Gambia, living in Gabon, and living in Ghana. That is, why shouldn't the examples in (29) all be true, too?
a. Elephants live in Gabon.
b. Elephants live in Gambia.
c. Elephants live in Ghana.

It's useful to note that this is a question one could ask quite generally about generics. Any property has many determinables: for every property $F$, there are lots of other properties $G_{1}, \ldots, G_{n}$ such that anything that is $F$ must by

\footnotetext{
${ }^{16}$ I defend this proposal in detail in Nickel [2010a].
} 
necessity also have one of the Gs. Paradigmatically, colors and their shades stand in this relation. Anything that is red must, of necessity, be a specific shade of red such as burgundy or scarlet.

For ordinary quantified sentences, the inference (30) is clearly valid.

(30) Let $G_{1}, \ldots, G_{n}$ be all of the determinables of $F$. Then

$$
[Q x: A x](F(x)) \vdash[Q x: A x]\left(G_{1}(x) \vee G_{2}(x) \vee \cdots \vee G_{n}(x)\right)
$$

It's a necessary truth that the extension of $F$ precisely coincides with the union of the extensions of the $G \mathrm{~s}$, so anything true of the $F$ s will also be true of the $G$ s jointly. But for generics, this inference fails. It's true that tigers are striped, and that any striped tiger must have a particular pattern and arrangement of stripes. It does not follow that tigers have this pattern or that pattern or the other pattern or.... Mutatis mutandis for colors: lions are tan, and anything that's tan must be a specific shade of tan. But it doesn't follow from these facts that any generic of the form lions are such-and-such particular shade of tan is true, nor that the generic that predicates the disjunction of all of these shades is.

Thinking about this situation in terms of stable causal mechanisms can help explain why generics contrast with straightforwardly quantificational claims. It may well be a result of a stable mechanism that lions are tan or that tigers have stripes, but it may be quite random which particular shade or which particular pattern of stripes a lion or tiger exhibits. Likewise, selective pressures might make it the case that elephants are endemic to Africa without there there being any selective pressures that determine a more restrictive habitat. The geographic distribution of elephants within Africa might be quite random, which would entail that (29a)-(29c) are all false. ${ }^{17}$

So given just the semantics of generics, we can go some way towards explaining why there is conjunctive strengthening in (2). We can also explain why elephants live in Gabon, Gambia, or Ghana doesn't convey truths via conjunctive strengthening, since here, all of the disjuncts are false. But that can't be why we have such a hard time hearing (5), elephants live in Africa or give birth to live young, as conjunctively strengthened, since in this case, the two disjuncts are actually true. For that, we need a more substantive theory of the strengthening phenomenon itself.

\section{Conjunctive Strengthening}

Theories of conjunctive strengthening come in two basic flavors. On one, a sentence such as Jane may drink coffee or tea is semantically ambiguous between a disjunctive and a non-disjunctive reading. ${ }^{18}$ On the other, such a sentence is

\footnotetext{
${ }^{17}$ I haven't given a general account of how to individuate causal mechanisms for the purpose of interpretating a given generic. I've only pointed out that introducing ways of being normal and tying them to mechanisms doesn't raise any new problems.

${ }^{18}$ See, e.g., Simons [2005] and Zimmerman [2000].
} 
semantically univocal, and the stronger non-disjunctive construal is due to an implicature. Whether a semantic or a pragmatic approach is ultimately right is very much a matter of debate, as are their detailed implementations. Unfortunately, I need to a adopt a particular theory in order to investigate how the semantics from $\S 2$ interact with a theory of conjunctive strengthening that applies in non-generic cases. So while the discussion so far, especially the analogy between generics and straightforwardly existentially quantified sentences, is independent of any particular theory of conjunctive strengthening, the rest of the paper necessitates a choice. The theory I will adopt is due to Fox [2007], so let me briefly motivate that adoption.

Three kinds of data are relevant. We have already seen the first, that conjunctive strengthening is sometimes available outside the scope of modal operators. This already speaks against semantic accounts, on which a sentence like Jane may drink coffee or tea is ambiguous, since these usually derive conjunctive strengthening as an interaction between disjunction and the modal operator. ${ }^{19}$

More positive reasons for a pragmatic account arise from the observation [due to Alonso-Ovalle, 2005] that conjunctive strengthening disappears in environments in which scalar implicatures quite generally are suspended, as illustrated in the parallel between (31) and (32).
a. Jones has two children.
(implicature present)

b. Every parent with two children is exhausted.

(implicature absent)
a. Jane may have coffee or tea.
(strengthening present)
b. Nobody may have coffee or tea.
(strengthening absent)

However, if we treat implicatures along the traditional Gricean lines, another fact about conjunctive strengthening is problematic. As (33) illustrates, it is available in some unasserted environments, such as the antecedents of conditionals. ${ }^{20}$

(33) (Usually, Jane may only have tea. So) if Jane may have coffee or tea, she'll be very pleased.

But on a traditional Gricean view, we predict that scalar implicatures are only present when a sentence is asserted, since that the sentence is asserted is one of the essential premises in a Gricean derivation.

I adopt Fox's theory of conjunctive strengthening because it is compatible with all three observations. It is explicitly designed to account for conjunctive strengthening in non-modal contexts such as existentially quantified sentences, it is an implicature-based theory, but it is couched within the non-Gricean framework of compositional implicature computation due to the work of Chierchia

\footnotetext{
${ }^{19}$ See in particular Simons [2005]. This point applies less forcefully to Zimmerman's account, on which disjunctions are understood as epistemic alternatives, so that they behave as if they were always in the scope of a modal operator.

${ }^{20}$ This has been noted by Alonso-Ovalle [2005], Kamp [1978].
} 
$[2002] .{ }^{21}$ It is this last fact that allows Fox's account to predict that conjunctive strengthening is available in some unasserted environments. ${ }^{22}$

\subsection{An Informal Presentation of Fox [2007]}

I'll present Fox's theory by explaining how one might arrive at it in response to some concerns about the traditional account of scalar implicatures inspired by Grice [1991]. This discussion will be informal. I provide explicit treatments of the core cases in the appendices.

Consider an assertion of a schematic disjunction (34).

(34) $p \vee q$.

According to Grice, the audience reasons about the assertion and the speaker's mental state as follows. By the maxim of quantity (be as informative as possible), if the speaker believed a proposition that is both stronger than the disjunction and relevant to the matter at hand, she should have asserted that stronger proposition. The reason the speaker didn't do so must be due to her following the maxim of quality (only say what you believe to be true). The audience thus infers (35a)-(35c).
a. $S$ does not believe $p$.
b. $S$ does not believe $q$.
c. $S$ does not believe $p \wedge q$.

The audience then reasons further, based on the assumption that the speaker is more opinionated than is reflected in these conclusions. So long as it is consistent with what we just inferred about the speaker's lack of commitment, the audience should assume that the reason the speaker doesn't believe a proposition is that she believes the proposition to be false, rather than simply being agnostic. The audience thus strengthens (35c) into the outright denial (36).

(36) $S$ believes $\neg(p \wedge q)$.

We cannot strengthen either (35a) or (35b) in an analogous way because doing so for one would conflict with the other. If we tried to strengthen (35a) into the outright denial that $S$ believes that $\neg p$, then given that $S$ asserted (34), it would follow that $S$ believes $q$, contradicting (35b). Thus the traditional account.

The so-called symmetry problem begins with the observation that (35) reflects an incomplete list of propositions that are strictly stronger than (34) and relevant to the matters at hand. ${ }^{23}$ We should also include $(p \vee q) \wedge \neg(p \wedge q)$ as

\footnotetext{
${ }^{21}$ For further motivation, see Chierchia et al. [2010]. For some recent criticism, see Greenhall [2008] and references therein.

${ }^{22}$ The proposal of Klinedinst [2007] shares these features with Fox's. I'll work with Fox's treatment because applying Klinedinst's to my data is rather cumbersome, though there aren't any technical obstacles.

${ }^{23}$ See Harnish [1991].
} 
something the speaker could have said, since it is obviously stronger than (34), and given that $(p \wedge q)$ is relevant, $\neg(p \wedge q)$ should be relevant, too. Thus, the speaker's ignorance should really be amended to include (35d).
a. $S$ does not believe $p$.
b. $S$ does not believe $q$.
c. $S$ does not believe $p \wedge q$.
d. $S$ does not believe $\neg(p \wedge q)$.

Strictu dictu, (35d) should read $S$ does not believe $(p \vee q) \wedge \neg(p \wedge q)$, but since the speaker actually asserted $p \vee q$, that entails (35d). And if (35d) is included among the speaker's ignorance, the attempt to strengthen (35c) into (36) is blocked in exactly the same way that the attempt to strengthen (35a) and (35b) into outright denials is.

A solution to this problem that tries to save as much of the traditional Gricean framework as possible is presented in Sauerland [2004], making use of the Horn-scales introduced by Horn [1972]. It excludes by stipulation, at least for the purposes of implicature calculation, $(p \vee q) \wedge \neg(p \wedge q)$ as an alternative proposition the speaker could have asserted. This blocks the inference to (35d), in turn freeing up the strengthening of (35c) into (36). Theoretically, this means that a general pragmatic principle that is supposed to be motivated by considerations that apply equally to all cooperative action, the maxim of quantity, has to be sensitive to a purely linguistic stipulation, the Horn-scale for the particular scalar item we are considering. One might thus at least consider an alternative way of making use of a stipulated set of alternatives in generating implicatures in which the maxim of quantity still plays a role, but in which the relationship between the maxim and the stipulated alternatives required to avoid the symmetry problem is less direct. That is the basic idea behind Fox's theory.

Just as on the Gricean account, we begin by reasoning about the speaker's mental state in accordance with the maxim of quantity which is not restricted by any stipulated set of alternatives. Thus, on Fox's account, an assertion of (34) will lead a speaker to infer all of (35a)-(35d). But in some situations, it may be implausible to think that the speaker is so thoroughly agnostic. This makes it plausible that the speaker actually expressed a different proposition, which in turn triggers a reinterpretation of the asserted sentence. Rather than treating it as expressing the simple disjunction, it is interpreted as strengthened by the addition of an exhaustivity operator, EXH. ${ }^{24}$ The basic semantics of that operator are modelled on those of only, motivated by the observation that an assertion of (37a) will license an audience to infer (37b) (with stress on or), which entails $(37 \mathrm{c}){ }^{25}$

\footnotetext{
${ }^{24}$ Thus, given an utterance of a sentence, the audience always faces the question whether the speaker's use of the sentence contained the exhausitvity operator or not, and the reasoning about the speaker's ignorance is the mechanism by which the audience arrives at the correct answer to that question.

${ }^{25}$ It's important to distinguish that stress from an interpretation on which the whole phrase Bill or Sue is focused and which means that John talked at most to Bill and Sue, no one else.
} 

a. John talked to Bill or Sue.
b. John only talked to Bill or Sue.
c. John did not talk to Bill and Sue.

Thus, ExH has roughly the meaning that the original sentence is true and that it is implicated that some stronger alternatives are false. It is at this point that the stipulation of alternatives required to avoid the symmetry problem appears.

The EXH operator takes a sentence as argument and a set of alternatives as another argument, and it has the output that the original sentence is asserted to be true and that some, though not necessarily all, of the alternatives are implicated to be false. In addition to the EXH operator itself, Fox's account thus has another component, one that corresponds to the selection principle I presented as part of the Gricean picture. Recall that on the traditional view, and quite independently of the symmetry problem, we couldn't simply convert every piece of ignorance we attribute to the speaker on the basis of reasoning in accord with the maxim of quantity into an outright denial. Instead, we had to make a selection, blocking for example the implicature that the speaker believes that $\neg p$, based on an assertion of $p \vee q$.

That we need a corresponding mechanism for Fox's account may at first sight seem surprising. After all, the standard Horn-scale for or is just $\{$ or, and $\}$, so that if these are the alternatives relevant for the computation of implicatures via the EXH operator, we don't need any further selection mechanism. For in that case, $p \wedge q$ is the only alternative, and if EXH generates the implicature that all of the stronger alternatives are false, we get exactly the right result, the implicature $\neg(p \wedge q)$. However, we have good reason to think that the set of scalar items determining the alternatives is what Sauerland calls $\{$ or, $L, R$, and $\}$, where $p L q$ is equivalent to $p$ (the "left" disjunct) and $p R q$ equivalent to $q$ (the "right" disjunct) ${ }^{26}$

So given that $p$ is an alternative to $p \vee q$ that serves as an argument for EXH, we need to ensure that the operator doesn't deliver the result that when $p \vee q$ is reinterpreted by EXH, it implicates that $\neg p$. Fox accomplishes this by defining a notion of innocent exclusion. Its main idea is that EXH does not implicate the falsity of a stronger alternative if doing so would entail (perhaps together with the asserted content) that another of these alternative is true. In this example, if we were to predict an implicature of $\neg p, q$ would follow, which is one of the other alternatives. Innocent exclusion thus quite directly parallels the constraints on the strengthening mechanism that is part of the traditional Gricean account.

By way of summary, here are the formal definitions of the ExH operator and the notion of innocent exclusion I just introduced.

\section{semantics for exh}

\footnotetext{
${ }^{26}$ This set is required to accurately predict the implicatures we observe when the scalar items appear in a downward entailing context. This is true both of a Neo-Gricean account of implicatures such as Sauerland [2004] and the compositional account I am describing here. For discussion, see Sauerland [2004].
} 
$\llbracket \operatorname{EXH} \rrbracket\left(\mathrm{ALT}_{\llbracket S \rrbracket}\right)(\llbracket S \rrbracket(w)) \Leftrightarrow$

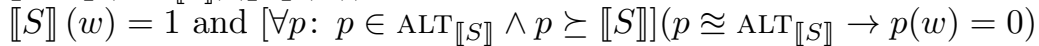

\section{innocent exclusion}

$$
p \approx \operatorname{ALT}_{\llbracket S \rrbracket} \text { if }\left(\neg \exists q: q \in \operatorname{ALT}_{\llbracket S \rrbracket} \wedge q \succeq \llbracket S \rrbracket\right](\llbracket S \rrbracket \wedge \neg p \vdash q)
$$

Here, $p \succeq \llbracket S \rrbracket$ should be read as $p$ is not weaker than $\llbracket S \rrbracket$, and $p \approx \mathrm{ALT}_{\llbracket S \rrbracket}$ as $p$ is innocently excludable given $\mathrm{ALT}_{\llbracket S \rrbracket}$. In words, applying the EXH operator to a sentence is equivalent to the assertion of that sentence together with the implicated negation of all of those members of the set of alternatives that are both no weaker than the sentence and can be innocently excluded.

I want to say something about the basic architecture of this kind of view, because it diverges from the Gricean mechanism in what it takes the basic nature of an implicature to be. On Grice's view, an implicature is something that a speaker makes or conveys, and it is related to the sentence used only insofar as the use of the sentence triggers a chain of reasoning that terminates in the audience's computing the implicature. But crucially on Grice's view, there is absolutely nothing in the sentence that reflects the implicated content.

The alternative conception that I am taking over from Fox's account sees implicatures as much more parallel to certain lexically triggered presuppositions. On this view, neither presuppositions nor implicatures are part of the assertoric content of the sentence as can be seen in the different effects embedding has on assertoric, presupposed, and implicated content. But unlike the standard Gricean view, this alternative conception locates the source of a scalar implicature in a syntactically real, albeit not phonetically realized, operator that influences assertoric and implicated content, just as only influences both assertoric and presupposed content. On this view, reasoning about the speaker's mental state on the basis of her assertion and what she could have said still plays a role, but only insofar as this triggers a reinterpretation making use of EXH.

Thus, the operator-view of implicatures agrees with Grice's original description of implicatures as content that is conveyed without influencing the assertoric content of the sentence. Grice further held that many different kinds of implicature, including scalar and relevance implicature, all reflect the same kind of reasoning. The operator-view of implicatures disagrees with Grice with respect to the uniformity of the phenomena. It agrees that relevance implicatures aren't the result of reinterpretation with an operator, but it disagrees with Grice in taking scalar implicatures to be the result of a different interpretive mechanism, one that does make use of such an operator.

\subsection{Application of the Theory}

One reason to prefer this kind of account, which derives implicatures via the reinterpretation of a sentence using the dedicated operator EXH is on display in the derivation of conjunctive strengthening. The process which leads to reinterpretation can in principle take place multiple times. Here, I'll only describe the crucial components of the derivation. For the full presentation, see appendix A. 
Suppose we start with the assertion of an existentially quantified sentence of the form (38).

(38) $(\exists x)(F x \vee G x)$

Reasoning in accordance with the maxim of quantity, the audience will conclude that the speaker's ignorance includes both (39a) and (39b).
a. $S$ does not believe $(\exists x)(F x)$.
b. $S$ does not believe $(\exists x)(G x)$.

That the speaker is agnostic in this way may be implausible, and if it is, the audience reinterprets the original assertion by adding an EXH. However, the application of EXH does not generate any of (40a)-(40d) as implicatures because none of them can be innocently excluded.
a. $S$ believes $(\exists x)(F x)$.
b. $S$ believes $(\exists x)(G x)$.
c. $S$ believes $\neg(\exists x)(F x)$.
d. $S$ believes $\neg(\exists x)(G x)$.

So if the audience once again reasons about the strengthened version of (38) in accord with the maxim of quantity, she will conclude again that (39a) and (39b) are true. Given that this was implausible enough to trigger the first reinterpretation, it must be implausible enough to trigger another reinterpretation, so that EXH is applied twice to the original sentence. That second application yields (40a) and (40b) as implicatures, i.e., the attested conjunctive strengthening.

If we apply the same strategy to the generic case, we get a completely parallel derivation of the conjunctive strengthening (for details, please consult appendix B). Given an assertion of (2), elephants live in Africa or Asia, the audience initially infers both (41a) and (41b).

a. $S$ does not believe that elephants live in Africa.

b. $S$ does not believe that elephants live in Asia.

This may be implausible. If it is, we reinterpret using ExH, but the first application does not yield implicatures that remove the agnosticism captured in (41a) and (41b). It is here that HOMOGENEITY is required. Without it, we would actually predict that an assertion of (2) implicates both (42a) and (42b).

a. $S$ believes that it's false that elephants live in Africa.

b. $S$ believes that it's false that elephants live in Asia.

This would directly contravene the attested conjunctive strengthening. But with HOMOGENEITY in place, another application of EXH is triggered, with the result that both (2a) and (2b) are implicated.

(2) a. Elephants live in Africa.

b. Elephants live in Asia.

We thus have an account of conjunctive strengthening in generics. 


\section{The Unavailability of Conjunctive Strength- ening}

The remainder of the paper will be concerned with the contrasting data, beginning with the pattern we see in (5), repeated here.

(5) Elephants live in Africa or give birth to live young.

a. $\Varangle$ Elephants live in Africa.

b. $\not \rightarrow$ Elephants give birth to live young.

Clearly, conjunctive strengthening is unavailable, so that (5) can only be used to convey the purely disjunctive proposition that either (5a) or (5b) is true. And given that limitation, (5) strikes us as odd, since it is extremely hard for us to imagine someone being in the epistemic state in which (5) is just the right thing to say. But why is conjunctive strengthening unavailable? It would seem that the ignorance we attribute to the speaker and that makes (5) odd for us should precisely trigger a reinterpretation of that sentence using the EXH operator and thus generate the parallel conjunctive strengthening. Yet the application of EXH doesn't deliver that result, the sentence cannot be conjunctively strengthened, and the assertion cannot be saved.

My account of why (5) doesn't allow for conjunctive strengthening, even though it is reinterpreted with EXH, has two parts. The first is a consequence of Fox's system. A sentence containing an existential quantifier and a disjunction gives rise to the conjunctive strengthening implicature only if the disjunction has narrow scope with respect to the existential quantifier. ${ }^{27}$ That is, applying Fox's EXH-operator to a sentence of the form $(\exists x)(F x \vee G x)$ yields a conjunctive strengthening, while applying it to $((\exists x)(F x) \vee(\exists x)(G x))$ does not. ${ }^{28}$

I want to exploit this feature of Fox's system by arguing that generics with logically complex verb phrases (VPs) are ambiguous between a reading on which the generic operator takes scope over the logical operators in the VP and a reading on which it is within the scope of the logical operators. Moreover, the semantics of the generic operator don't always allow both scope possibilities. In the case of (5), for example, we cannot interpret the generic operator as having scope over the disjunction in the VP, and hence we predict that (5) cannot be conjunctively strengthened in Fox's system.

\footnotetext{
${ }^{27} \mathrm{I}$ already observed this fact informally in the introduction, both for permission sentences and generics. See p. 2.

${ }^{28} \mathrm{An}$ attempted derivation of a conjunctively strengthened meaning for $((\exists x)(F x) \vee$ $(\exists x)(G x))$ crashes at the end. The first application of ExH yields the result $((\exists x)(F x) \vee$ $(\exists x)(G x)) \wedge \neg((\exists x)(F x) \wedge(\exists x)(G x))$. When we apply the ExH operator again, we have to compute the alternatives that correspond to (a)-(c) on p. 29. The alternatives that correspond to (a) and (b) are the same in this case, but while we could innocently exclude (a) in the earlier derivation, we cannot innocently exclude it in this one. That's because to innocently exclude it, the result of the strengthened meaning, together with the negation of (a), would have to not entail (b). But it does: $((\exists x)(F x) \vee(\exists x)(G x)) \wedge \neg((\exists x)(F x) \wedge(\exists x)(G x))$ together with $\neg((\exists x)(F x) \wedge \neg(\exists x)(G x))$ does entail (b), $(\neg(\exists x)(F x) \wedge(\exists x)(G x))$.
} 


\subsection{The LF of Generics}

In $\S 2.2$ I regimented generics in terms of a generic operator, but I did not commit myself to any particular LF for generics. I now need to be more explicit on this issue, because constraints on LFs determine available readings for generics. The most common analyses of generics treat the generic operator as either a nominal determiner or as an adverb of quantification. ${ }^{29}$ So to a good first approximation, the LF of (43) is either (43a) or (43b). ${ }^{30}$

(43) Ravens are black.

a.

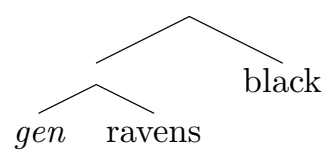

b.

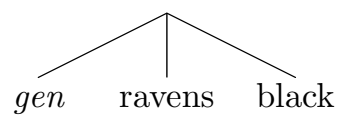

One reason to be dissatisfied with either of these options stems from the wellformedness of sentences such as those in (44). ${ }^{31}$

a. Diamonds are rare and valuable.

b. Pandas are black and white and endangered.

On either analysis, these sentences should be incoherent because they contain one predicate that needs to be analyzed by using the generic operator (valuable and black and white), and another predicate that cannot be so analyzed because it applies directly to the kind (rare and endangered). But on both analyses, either both predicates are in the scope of the generic operator or neither is. To see the point intuitively, consider the malformedness of the examples in (45).

$$
\begin{array}{r}
\text { Most } \\
\text { All normal } \\
\text { Usually } \\
\text { b. } \left.\begin{array}{r}
\text { Typically } \\
\text { Generally } \\
\text { Normally }
\end{array}\right\} \text { diamonds are such that they are rare and valuable. }
\end{array}
$$

I suggest that we reconceive the LF of generics by modeling it very closely on the LF of non-generic plurals, focusing particularly on the difference between their collective and distributive readings. The basic contrast is exhibited by the pair in (46).

\footnotetext{
${ }^{29}$ See Asher and Morreau [1995], Krifka et al. [1995]) for the determiner analysis and Cohen [1999a,b], Wilkinson [1991] for the adverbial analysis.

${ }^{30} \mathrm{I}$ 'm assuming a ternary branching structure for adverbs of quantification, following Heim [1982].

${ }^{31}$ See, e.g., Schubert and Pelletier [1989] for discussion.
} 
(46) a. The children woke up at eight.

b. The children gathered in the yard.

(46a) licenses the inference that each child woke up at eight, making it distributive. (46b) does not license the corresponding inference that each child gathered in the yard, making it collective. In fact, an individual child cannot gather. The predicate applies to the children as a whole. The standard treatment of the collective/distributive contrast posits a distributive quantifier in the LF of distributively read sentences, so that at the level of LF, (46a) is analyzed roughly as (47).

(47) The children are such that for each child among them, it woke up at eight.

Just as in the case of generics, there are alternative proposals regarding where in the LF the distributive quantifier originates. Here, the options are to analyze it as part of the plural NP or to analyze it as part of the VP. ${ }^{32}$ Many theorists prefer the VP-analysis because of examples like (48).

(48) The children woke up at eight and gathered in the yard.

If we treated the distributive operator as part of the NP, we'd predict that (48) meant that the children are such that each one among them woke up at eight and gathered in the yard, which is incoherent. However, if we analyze the distributive operator as part of the VP, we have two options, sketched in (49), where $D$ is the distributive operator.

a.

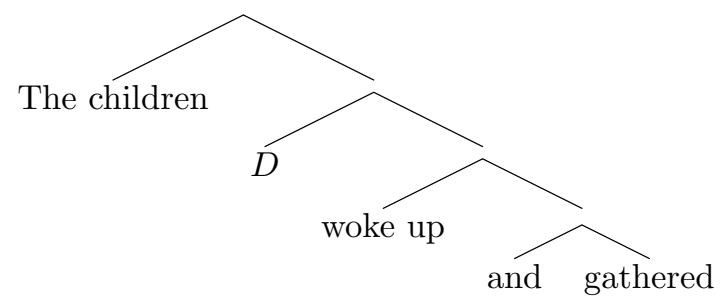

b.

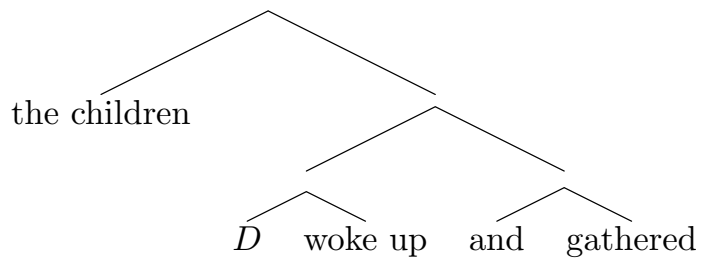

(49a) corresponds to the incoherent reading, while (49b) is coherent. It says that the children are such that for each one among them, it woke up, and they gathered in the yard. ${ }^{33}$

\footnotetext{
${ }^{32}$ See, e.g., Gillon [1987, 1990, 1992], Lakoff [1972] for the NP-analysis, Beck and Sauerland [2000], Landmann [2000], Lasersohn [1995], McKay [2006], Pietroski [2005], Schein [1993], Schwarzschild [1996], Winter [2000] for the VP-analysis.

${ }^{33}$ In a class on plurals, Irene Heim has suggested that this argument for a VP-analysis of distributivity can be resisted if we posit a duplication of the NP in (48).
} 
The parallel between generics and non-generic plurals is striking. Both allow for predicates that are best interpreted in terms of an operator that relates them to the individuals picked out by the subject term, and both allow for predicates that cannot be so interpreted. And both allow for both kinds of predicates to be conjoined in a single VP. I suggest that we take the parallel between generics and non-generic plurals seriously and analyze the generic operator as part of the $\mathrm{VP}$, precisely in the way that the distributive operator $D$ is analyzed as part of the VP. Thus, the basic generic elephants live in Africa is assigned the LF in (50).

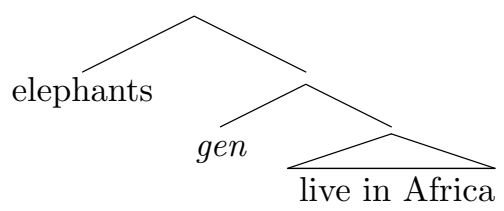

Just as we have different options for analyzing how the simple distributive operator interacts with logically complex VPs, as illustrated in (49a) and (49b), we have similar options for the generic operator. The generic operator can attach high in the complex VP or to each predicate making up that VP.

(51) Diamonds are rare and valuable.

a.

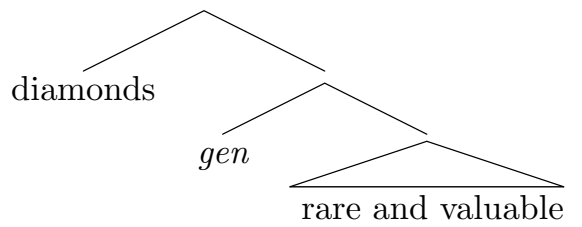

b. Diamonds are such that each of generically many among them are both rare and valuable.

c.

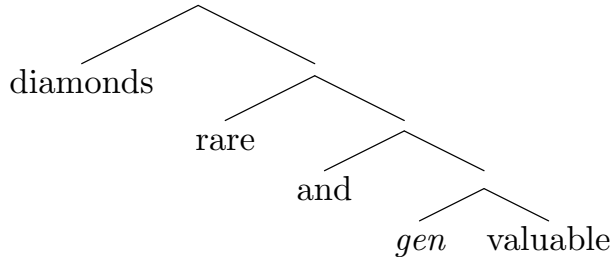

d. Diamonds are such that they are rare and each of generically many among them are valuable.

(51a) yields the incoherent interpretation rendered informally by (51b), while (51c) yields the intuitively correct interpretation glossed in (51d). Given these options, we also have two possible LFs for the sentence (5), repeated here as (52).

(52) Elephants live in Africa or give birth to live young. 
a.

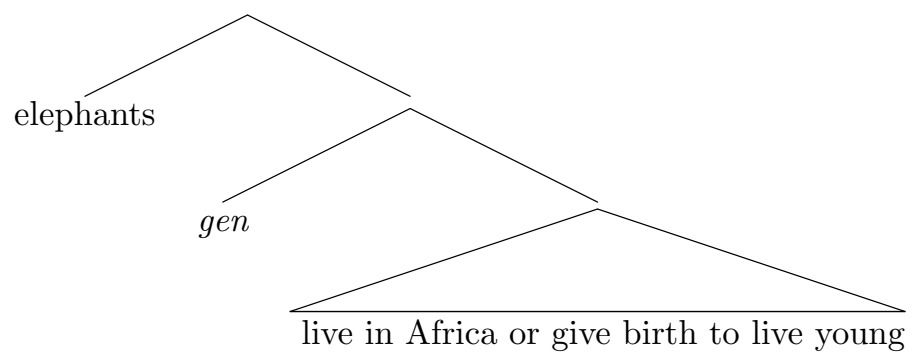

b.

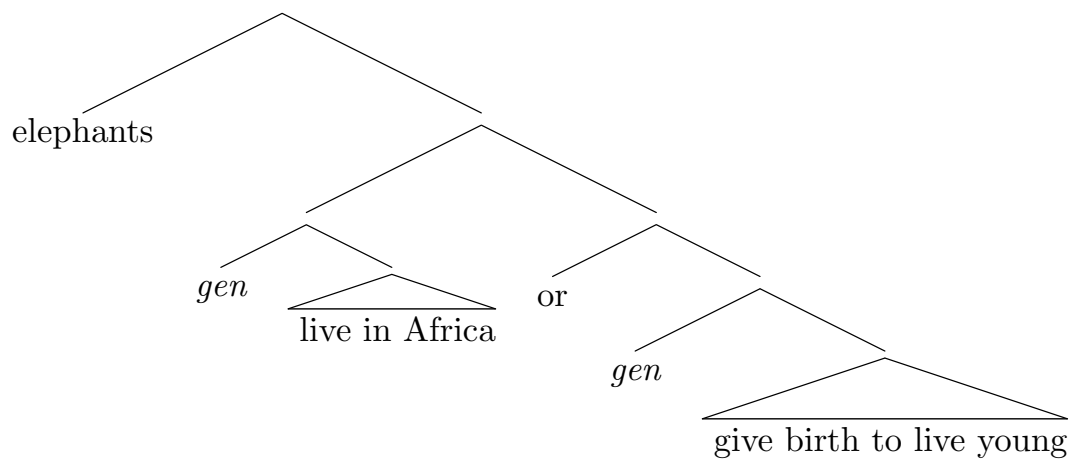

(52a) gives rise to an interpretation of (52) on which the generic operator has wide scope with respect to the whole predicate. On this interpretation, Fox's system predicts that (52) can be conjunctively strengthened. (52b) gives rise to an interpretation with two generic operators, neither of which has wide scope with respect to the disjunction-it's equivalent to the sentential disjunction elephants live in Africa or elephants give birth to live young. That interpretation does not allow for conjunctive strengthening.

\subsection{Respects of Normality}

The fact that there are two possible LFs for (5) shows that it's possible for an assertion of (5) to not be conjunctively strengthened, even when the agnosticism we attribute to the speaker is sufficiently implausible to trigger a reinterpretation with ExH. But that's not enough to account for the data, since I have yet to explain why (5) cannot be so strengthened. In other words, I need an explanation for why the LF (52a) is ruled out as a possible LF of (5).

The reason turns on how the generic operator is interpreted. Recall that in interpreting a generic, we always have to restrict the domain of the quantifier to members of the kind at issue that are normal in a certain respect. This respect, in turn, is determined by the predicate: if (for instance) we predicate being black, then the respect of normality is color. But a disjunction may not always determine a unique respect of normality. One reason for such a failure is that each of the disjuncts determines a different respect of normality, in which case these two respects cannot be amalgamated. That is precisely what happens when we interpret (5). If we wanted to assign truth-conditions based on the 
LF (52a) - with the disjunction taking narrow scope under gen - we would have to find a respect of normality of which living in Africa and giving birth to live young are both instances. But there is no such respect, and hence that LF is not interpretable. Only the wide-scope disjunction LF (52a) remains. By contrast, the two disjuncts in (2) determine the same respect of normality, being normal with respect to habitat, which is why the LF that assigns the disjunction narrow scope is interpretable and conjunctive strengthening is available.

One kind of support for this analysis of the contrast between (2) and (5) as concerns the availability of conjunctive strengthening derives from cases that are on the borderline between allowing it and not. Ordinarily, we cannot use conjunctive strengthening to convey something about the color of an elephant's tusk and the color of its ears. At least initially, (53) seems to be about as odd as (5).

(53) Elephants have gray ears or white tusks.

Given what we think about how elephants come by their gray ears and white tusks, we take each disjunct as corresponding to the operation of a separate mechanism. We don't expect an elephant that lacks one to lack the other, to give just one indication of this separateness. But given the right background, we can detect conjunctive strengthening for a disjunction about ear color and tusk color. Just suppose that there is a virus that can manifest with one two symptoms: pink ears or blue tusks. In that case, (54) can unproblematically give rise to conjunctive strengthening.

(54) Diseased elephants have pink ears or blue tusks.

The background story allows us to analyze these two features as instances of the same respect of normality - normal disease symptoms for diseased elephantsand this in turn allows us to analyze (54) with a single generic operator that takes scope over the whole disjunctive VP, which in turn gives rise to conjunctive strengthening if a reinterpretation with EXH is triggered.

\section{Conclusion}

In this paper, I've observed that some generics with disjunctive predicates can be used to convey conjunctions of simpler generics while other similarly complex generics don't allow this. I've argued that we can account for the possibility of conjunctive strengthening of the former, as well as the impossibility of the strengthening for the latter, using five basic ideas: we interpret generics in terms of a sophisticated notion of normality that (1) makes reference to respects of normality and (2) recognizes ways of being normal in a given respect. The generic quantifier (3) occupies the same position as a distributive quantifier in non-generic plurals and (4) obeys HOMOGENEITY. (5) Conjunctive strengthening arises in accordance with Fox's account. Each of these five building blocks can be motivated on grounds that are independent of the specific phenomena 
discussed here. The fact that they also account for conjunctive strengthening in generics adds credibility to their applications in other contexts.

A broader issue stands in the background of this discussion. One of the most striking facts about generics is the broad range of interpretations they exhibit, a range that is available in the face of extreme surface simplicity. Impressionistically, there are two semantic strategies to deal with this fact. On one, the LF of generics is extremely simple, and the varities of interpretation arise because of some extra-semantic factors. The most prominent instance of this strategy is the original kind-predicating analysis of generics in Carlson [1977, 2002]. On another, the LF of generics is quite complex, or perhaps better, contains a generic operator with very complex semantic properties. The present discussion speaks strongly in favor of the latter option, since we can see that which formally possible interpretations are actually available in a context depends on quite specific information about the subject matter of the generic. This in turn argues for the hypothesis that such information is encoded in the LF of generics. And more generally, it suggests that we may be more optimistic about accounting for many aspects of the interpretation of generics within semantics. 


\section{A Conjunctive Strengthening in A Simple Ex- istential}

In order to improve legibility, I won't explicitly distinguish between content that counts as asserted and content that counts as implicated.

Assertion: $\llbracket S \rrbracket=(\exists x)(F x \vee G x)$

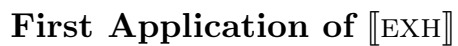

Doing so generates the formula

$$
\llbracket \mathrm{EXH} \rrbracket\left(\mathrm{ALT}_{\llbracket S \rrbracket}\right)((\exists x)(F x \vee G x))
$$

The alternatives $\mathrm{ALT}_{\llbracket S \rrbracket}$ are

(a) $(\exists x)(F x)$

(b) $(\exists x)(G x)$

(c) $(\exists x)(F x \wedge G x)$

Computation of $\llbracket \mathrm{EXH} \rrbracket\left(\mathrm{ALT}_{\llbracket S \rrbracket) \llbracket S \rrbracket}\right.$

Can (a) be innocently excluded? - No, because $\llbracket S \rrbracket \wedge \neg(\exists x)(F x)$ entails $(\exists x)(G x)$, which is a member of the alternatives in $\mathrm{ALT}_{\llbracket S \rrbracket}$, and which isn't weaker than $\llbracket S \rrbracket$. By parallel reasoning, (b) cannot be innocently excluded. (c), however, can be innocently excluded. Therefore,

$$
\llbracket \mathrm{EXH} \rrbracket\left(\mathrm{ALT}_{\llbracket S \rrbracket}\right) \llbracket S \rrbracket=(\exists x)(F x \vee G x) \wedge \neg(\exists x)(F x \wedge G x)
$$

Second Application of $\llbracket \mathrm{EXH} \rrbracket$

Doing so generates the formula

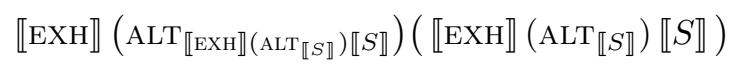

The alternatives $\mathrm{ALT}_{\llbracket \mathrm{ExH} \rrbracket\left(\mathrm{ALT}_{\llbracket S \rrbracket}\right) \llbracket S \rrbracket}$ are:

(a) $\llbracket \mathrm{EXH} \rrbracket\left(\mathrm{ALT}_{\llbracket S \rrbracket}\right)((\exists x)(F x))$.

(b) $\llbracket \mathrm{EXH} \rrbracket\left(\mathrm{ALT}_{\llbracket S \rrbracket}\right)((\exists x)(G x))$.

(c) $\llbracket \mathrm{EXH} \rrbracket\left(\mathrm{ALT}_{\llbracket S \rrbracket}\right)((\exists x)(F x \wedge G x))$. 
Computation of the Alternatives (a)-(c)

Begin with (a), $\llbracket \mathrm{EXH} \rrbracket\left(\mathrm{ALT}_{\llbracket S \rrbracket}\right)((\exists x)(F x))$. The non-weaker alternatives to $(\exists x)(F x)$ in $\mathrm{ALT}_{\llbracket S \rrbracket}$ are:

$$
\begin{aligned}
(\mathrm{d}) \quad * . & (\exists x)(G x) \\
& \dagger .(\exists x)(F x \wedge G x)
\end{aligned}
$$

$(\mathrm{d} *)$ can be innocently excluded. $(\mathrm{d} \dagger)$ can be innocently excluded, too, but doing so adds no extra information, since $(\mathrm{d} \dagger)$ has already been excluded in the initial application of $\llbracket \mathrm{EXH} \rrbracket$. Thus,

$$
\llbracket \mathrm{EXH} \rrbracket\left(\operatorname{ALT}_{\llbracket S \rrbracket}\right)((\exists x)(F x))=(\exists x)(F x) \wedge \neg(\exists x)(G x)
$$

By parallel reasoning, we can compute the value of (b) as

$$
\llbracket \mathrm{EXH} \rrbracket\left(\mathrm{ALT}_{\llbracket S \rrbracket}\right)((\exists x)(G x))=(\exists x)(G x) \wedge \neg(\exists x)(F x)
$$

Computing (c) is trivial, since there are no non-weaker alternatives to it in $\mathrm{ALT}_{\llbracket S \rrbracket}$. Thus,

$$
\llbracket \mathrm{EXH} \rrbracket\left(\mathrm{ALT}_{\llbracket S \rrbracket}\right)((\exists x)(F x \wedge G x))=(\exists x)(F x \wedge G x)
$$

\section{Return to the Computation of}

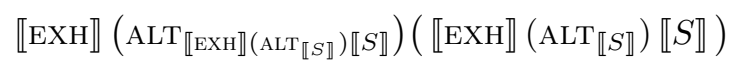

Can (a) be innocently excluded? That is, does the conjunction

$$
(\exists x)(F x \vee G x) \wedge \neg(\exists x)(F x \wedge G x) \wedge \neg((\exists x)(F x) \wedge \neg(\exists x)(G x))
$$

entail either (b) or (c)? It entails neither. Hence, (a) is innocently excludable. By parallel reasoning, (b) is innocently excludable. (c) is also innocently excludable, but since it has already been excluded in the first application of $\llbracket \mathrm{EXH} \rrbracket$,

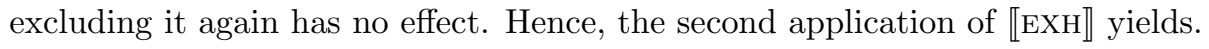

$$
\begin{aligned}
\llbracket \mathrm{EXH} \rrbracket\left(\mathrm{ALT}_{\llbracket S \rrbracket}\right) \llbracket S \rrbracket= & (\exists x)(F x \vee G x) \wedge \neg(\exists x)(F x \wedge G x) \wedge \\
& \neg((\exists x)(F x) \wedge \neg(\exists x)(G x)) \wedge \\
& \neg((\exists x)(G x) \wedge \neg(\exists x)(F x))
\end{aligned}
$$

Notice now that the last two conjuncts of this expression are equivalent to

$$
((\exists x)(F x)) \equiv((\exists x)(G x))
$$

Together with the first conjunct of this expression, this equivalence entails

$$
((\exists x)(F x)) \wedge((\exists x)(G x))
$$

which is exactly the conjunctive strengthening we wanted to predict. 


\section{B Derivation of Conjunctive Strengthening in Generics using GEN and HOMOGENEITY}

Consider the schematic case of a generic (55a).
a. As are $G$ or $H$.
b. $\operatorname{Gen}(A s ; G$ or $H)$
c. $[\exists N$ : Way.Of.Being.G-or-H-normal.A $(N)][\forall x: A(x) \wedge N(x)](G(x) \vee$ $H(x))$.
d. $[\exists N][\forall x: N x](G x \vee H x)$.

The regimentation of (55a) is given by (55b), which translates into the semantic proposal (55c). For reasons of legibility, I'll abbreviate (55c) as (55d). The more complex restrictors of the quantifiers play no role and could be expanded throughout the derivation to follow.

Assertion: $\llbracket S \rrbracket=[\exists N][\forall x: N x](G x \vee H x)$

First Application of $\llbracket \mathrm{EXH} \rrbracket$

Doing so generates the formula

$$
\llbracket \mathrm{EXH} \rrbracket\left(\mathrm{ALT}_{\llbracket S \rrbracket}\right)([\exists N][\forall x: N x](G x \vee H x))
$$

The alternatives $\mathrm{ALT}_{\llbracket S \rrbracket}$ are

(a) $[\exists N][\forall x: N x](G x)$

(b) $[\exists N][\forall x: N x](H x)$

(c) $[\exists N][\forall x: N x](G x \wedge H x)$

Computation of $\llbracket \mathrm{EXH} \rrbracket\left(\mathrm{ALT}_{\llbracket S \rrbracket}\right) \llbracket S \rrbracket$

Here, HOMOGENEITY is crucial. To see this, consider what would happen without it.

Can (a) be innocently excluded?-Yes, because

$$
[\exists N][\forall x: N x](G x \vee H x) \wedge \neg[\exists N][\forall x: N x](G x)
$$

does not entail either (b) or (c). To see this, it might help to remember that the predicate I'm abbreviating as $N x$ is just a predicate of objects in the domain. (a) says that there is some suitable way of restricting the domain of the quantifier (some property of the right kind picked out by $N$ ) so that only things that are either $G$ or $H$ are in that domain. (b) says that there is no suitable way of restricting the domain in such a way that it only contains things that are $G$. From that it doesn't follow that there's a suitable way of restricting the domain in such a way that it only contains things that are $H$, because it's compatible 
with the truth of (a) and (b) that the only suitable way of restricting the domain (the only way of being relevantly normal) is one that includes both things that are $G$ and things that are $H$ in the domain.

For parallel reasons, (b) can be innocently excluded. (c) can also be innocently excluded. Therefore,

$$
\begin{aligned}
\llbracket \mathrm{EXH} \rrbracket\left(\mathrm{ALT}_{\llbracket S \rrbracket}\right) \llbracket S \rrbracket= & {[\exists n][\forall x: N x](G x \vee H x) \wedge } \\
& \neg[\exists N][\forall x: N x](G x) \wedge \\
& \neg[\exists N][\forall x: N x](H x) \wedge \\
& \neg[\exists N][\forall x: \quad N x](G x \wedge H x)
\end{aligned}
$$

At this point, we have excluded precisely the propositions that are attested as conjunctive strengthenings, namely $[\exists N][\forall x: N x](G x)$ and $[\exists N][\forall x: N x](H x)$. Hence, a direct application of Fox's system to generics with disjunctive predicates in the absence of HOMOGENEITY fails to predict the attested conjunctive strengthening.

Adding HOMOgEneity Now consider what happens once we take account of HOMOGENEITY. The question, as before, is this: can we innocently exclude (a)? No. The negation of (a) is $\neg[\exists N][\forall x: N x](G x)$. This is equivalent to $[\forall N] \neg[\forall x: N x](G x)$. By HOMOGENEITY, this entails $[\forall N][\forall x: N x](\neg G x)$, which together with $\llbracket S \rrbracket$ entails (b). By parallel reasoning, we cannot innocently exclude (b), either. However, (c) can be innocently excluded. Thus

$$
\begin{aligned}
\llbracket \mathrm{EXH} \rrbracket\left(\mathrm{ALT}_{\llbracket S \rrbracket}\right)([\exists N][\forall x: N x](G x \vee H x))= & {[\exists N][\forall x: N x](G x \vee H x) \wedge } \\
& \neg[\exists N][\forall x: N x](G x \wedge H x)
\end{aligned}
$$

Second Application of $\llbracket \mathrm{EXH} \rrbracket$

Doing so generates the formula

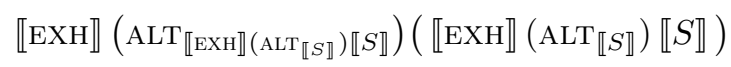

The alternatives $\operatorname{ALT}_{\llbracket \mathrm{ExH} \rrbracket\left(\mathrm{ALT}_{\llbracket S \rrbracket}\right) \llbracket S \rrbracket}$ are:

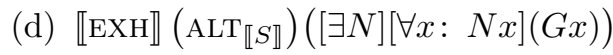

(e) $\llbracket \mathrm{EXH} \rrbracket\left(\mathrm{ALT}_{\llbracket S \rrbracket}\right)([\exists N][\forall x: N x](H x))$

(f) $\llbracket \mathrm{EXH} \rrbracket(\operatorname{ALT} \llbracket S \rrbracket)([\exists N][\forall x: N x](G x \wedge H x))$

Computation of the Alternatives (d)-(f) Begin with (d), $\llbracket \operatorname{EXH} \rrbracket\left(\operatorname{ALT}_{\llbracket S \rrbracket}\right)([\exists N][\forall x: N x](G x))$. The non-weaker alternatives to $[\exists N][\forall x: N x](G x)$ in $\mathrm{ALT}_{\llbracket S \rrbracket}$ are:

(d) *. $[\exists N][\forall x: N x](H x)$

†. $[\exists N][\forall x: N x](G x \wedge H x)$ 
$(\mathrm{d} *)$ can be innocently excluded. $(\mathrm{d} \dagger)$ can be innocently excluded, but doing so adds no extra information, since $(\mathrm{d} \dagger)$ has already been excluded in the initial

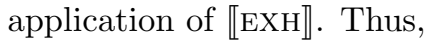

$$
\begin{aligned}
\llbracket \mathrm{EXH} \rrbracket\left(\mathrm{ALT}_{\llbracket S \rrbracket}\right)([\exists N][\forall x: N x](G x))= & {[\exists N][\forall x: N x](G x) \wedge } \\
& \neg[\exists N][\forall x: N x](H x)
\end{aligned}
$$

By parallel reasoning, we can compute the value of (e):

$$
\begin{aligned}
\llbracket \mathrm{EXH} \rrbracket\left(\mathrm{ALT}_{\llbracket S \rrbracket}\right)([\exists N][\forall x: N x](H x))= & {[\exists N][\forall x: N x](H x) \wedge } \\
& \neg[\exists N][\forall x: N x](G x)
\end{aligned}
$$

Computing (f) is trivial, since there are no non-weaker alternatives to $[\exists N][\forall x: N x](G x \wedge$ $H x))$ in $\mathrm{ALT}_{\llbracket S \rrbracket}$. Thus,

$$
\llbracket \mathrm{EXH} \rrbracket\left(\mathrm{ALT}_{\llbracket S \rrbracket}\right)([\exists N][\forall x: N x](G x \wedge H x))=[\exists N][\forall x: N x](G x \wedge H x)
$$

\section{Return to the Computation of}

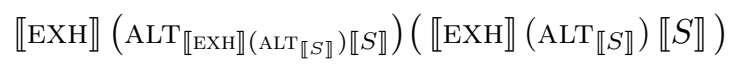

Can (d) be innocently excluded? That is, does the following entailment hold:

(i) $[\exists N][\forall x: N x](G x \vee H x) \wedge \neg[\exists n][\forall x: N x](G x \wedge H x)$

(ii) $\neg([\exists N][\forall x: N x](G x) \wedge \neg[\exists N][\forall x: N x](H x))$

$\therefore$ (iii) $[\exists N][\forall x: N x](H x) \wedge \neg[\exists N][\forall x: N x](G x)$

Here, (i) is the initial assertion (i.e., the result of the first application of $\llbracket \mathrm{EXH} \rrbracket$ ), (ii) the negation of the first alternative (d), (iii) the second alternative (e). This is the only entailment we need to check. To make the answer a little bit clearer, it may be useful to apply De Morgan's Law to the second premise (ii), yielding

$$
\left(\text { ii }^{\prime}\right) \neg[\exists N][\forall x: N x](G x) \vee[\exists N][\forall x: N x](H x)
$$

Here's a way of making the premises true and the conclusion false. Assign the value true to each of the conjuncts of (i), assign false to the first disjunct of $\left(\mathrm{ii}^{\prime}\right)$, true to the second disjunct of (ii'). In that case, the conclusion is false, since the first disjunct of (ii') just is one of the conjuncts of (iii), and hence the conclusion is false. Hence, (d) can be innocently excluded.

By parallel reasoning, (e) can be innocently excluded. (f) is also innocently

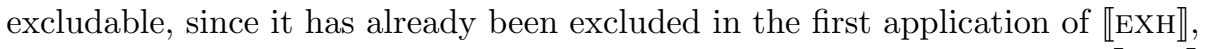

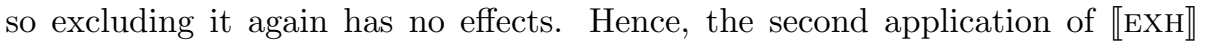
yields.

$$
\begin{aligned}
& ([\exists N][\forall x: N x](G x \vee H x) \wedge \neg[\exists n][\forall x: N x](G x \wedge H x)) \wedge \\
& \neg([\exists N][\forall x: N x](G x) \wedge \neg[\exists N][\forall x: N x](H x)) \wedge \\
& \neg([\exists N][\forall x: N x](H x) \wedge \neg[\exists N][\forall x: N x](G x))
\end{aligned}
$$


Once again, the last two conjuncts are equivalent to the biconditional

$$
([\exists N][\forall x: N x](G x)) \equiv([\exists n][\forall x: N x](H x))
$$

Together with the first conjunct, this equivalence entails

$$
([\exists N][\forall x: N x](G x)) \wedge([\exists n][\forall x: N x](H x))
$$

which is exactly the conjunctive strengthening we wanted to predict. 


\section{References}

Luis Alonso-Ovalle. Distributing the disjuncts over the modal space. In Leah Bateman and Cherlon Ussery, editors, Proceedings of the North East Linguistics Society, volume 35, Amherst, MA, 2005. GLSA. URL http://www. alonso-ovalle.net/papers/alonso-ovalleNELS2005.pdf.

Nicholas Asher and Michael Morreau. What some generic sentences mean. In Gregory N. Carlson and Francis Jeffry Pelletier, editors, The Generic Book, pages 300-339. University of Chicago Press, Chicago, 1995.

Jon Barwise. Conditionals and conditional information. In E. Traugott, A. ter Meulen, J. Snitzer-Reilly, and C. Ferguson, editors, On Conditionals, pages 21-54. Cambridge UP, Cambridge, UK, 1986.

Sigrid Beck and Uli Sauerland. Cumulation is needed: A reply to winter (2000). Natural Language Semantics, 8(4):349-371, 2000.

Christine Brisson. Plurals, all, and the nonuniformity of collective predication. Linguistics and Philosophy, 26(2):129-184, 2003.

Gregory N. Carlson. Reference to Kinds in English. PhD thesis, University of Massachusetts, Amherst, 1977.

Gregory N. Carlson. Truth conditions of generic sentences: Two contrasting views. In Gregory N. Carlson and Francis Jeffry Pelletier, editors, The Generic Book, pages 224-237. University of Chicago Press, Chicago, 1995.

Gregory N. Carlson. A unified analysis of the english bare plural. In Paul Portner and Barbara H. Partee, editors, Formal Semantics: The Essential Readings, pages 35-74. Blackwell Publishing, Malden, MA, 2002.

Gennaro Chierchia. Scalar implicature, polarity phenomena, and the syntax/pragmatics interface. In A. Belletti, editor, Structures and Beyond, pages 39-103. Oxford UP, Oxford, 2002.

Gennaro Chierchia, Danny Fox, and Benjamin Spector. The grammatical view of scalar implicatures and the relationship between semantics and pragmatics. to appear in Handbook of Semantics, edited by Portner et al., 2010. URL http://semanticsarchive.net/Archive/WMzY2ZmY/CFS_EmbeddedSIs.pdf.

Ariel Cohen. Generics, frequency adverbs, and probability. Linguistics and Philosophy, 22:221-253, 1999a.

Ariel Cohen. Think Generic! CSLI Publications, Stanford, CA, 1999b.

Ariel Cohen. Generics and mental representation. Linguistics and Philosophy, $27(5): 529-556,2004$.

Regine Eckardt. Normal objects, normal worlds, and the meaning of generics. Journal of Semantics, 16(3):237-278, 1999. 
Janet Dean Fodor. The Linguistic Description of Opaque Contexts. PhD thesis, MIT, 1970.

Danny Fox. Free choice and the theory of scalar implicatures. In Uli Sauerland and Penka Stateva, editors, Presupposition and Implicature in Compositional Semantics, pages 71-120. Palgrave Macmillan, Houndsmills, 2007.

Claudia Gerstner-Link. Über Generizität. Generische Nominalphrasen in singulären und generischen Aussagen. PhD thesis, University of Munich, 1988.

Brendan Gillon. The readings of plural noun phrases. Linguistics and Philosophy, 10(2):199-220, 1987.

Brendan Gillon. Plural noun phrases and their readings: A reply to lasersohn. Linguistics and Philosophy, 13(4):477-485, 1990.

Brendan Gillon. Towards a common semantics for english count and mass nouns. Linguistics and Philosophy, 15(6):597-640, 1992.

Yael Greenberg. Exceptions to generics: Where vagueness, context dependence and modality interact. Journal of Semantics, 24(2):131-167, 2007.

Owen Greenhall. Against chierchia's computational account of scalar implicatures. Proceedings of the Aristotelian Society, 108(1 (pt. 3)):373-384, 2008.

H.P. Grice. Logic and conversation. In Studies in the Ways of Words, pages 22-40. Harvard UP, Cambridge, 1991.

Robert M. Harnish. Logical form and implicature. In Steven Davis, editor, Pragmatics: A Reader, pages 316-364. Oxford UP, New York, 1991.

Irene Heim. The Semantics of Definite and Indefinite Noun Phrases. PhD thesis, University of Massachusetts, Amherst, 1982.

Larry R. Horn. On the Semantic Properties of Logical Operators in English. $\mathrm{PhD}$ thesis, University of California, Los Angeles, 1972.

Hans Kamp. Free choice permission. Proceedings of the Aristotelian Society, 74: 57-74, 1973.

Hans Kamp. Semantics vs. pragmatics. In F. Guenthner and S. J. Schmidt, editors, Formal Semantics and Pragmatics for Natural Language, pages 255287. Reidel, Dordrecht, 1978.

Nathan W. Klinedinst. Plurality and Possibility. PhD thesis, University of California, Los Angeles, 2007.

Manfred Krifka, Francis Jeffry Pelletier, Gregory N. Carlson, Alice ter Meulen, Gennaro Chierchia, and Godehard Link. Genericity: An introduction. In Gregory N. Carlson and Francis Jeffry Pelletier, editors, The Generic Book, pages 1-124. University of Chicago Press, Chicago, 1995. 
George Lakoff. Linguistics and natural logic. In Donald Davidson and Gilbert Harman, editors, Semantics of Natural Language. D. Reidel, Dordrecht, Holland, 1972.

Fred Landmann. Events and Plurality. Kluwer Academic, Dordrecht, 2000.

Peter Lasersohn. Plurality, Conjunction, and Events. Kluwer, Dordrecht, 1995.

David Liebesman. Simple generics. 2010. URL http://sites.google.com/site/davidliebesman/simple-generics/SGsfinal3. doc?attredirects=0. Forthcoming in Noûs.

C. C. Little. Coat color genes in rodents and carnivores. The Quarterly Review of Biology, 33(2):103-137, 1958.

John McCarthy. Circumscription: A form of non-monotonic reasoning. Artificial Intelligence, 13(1-2):27-39, 1980.

John McCarthy. Applications of circumscription to formalizing common sense knowledge. Artificial Intelligence, 28(1):89-116, 1986.

Thomas J. McKay. Plural Predication. Oxford UP, Oxford, 2006.

Bernhard Nickel. Generics and the ways of normality. Linguistics and Philosophy, 31(6):629-648, 2008.

Bernhard Nickel. Ceteris Paribus Laws: Genericity, and natural kinds. Philosophers' Imprint, 10(6):1-25, 2010a.

Bernhard Nickel. Generic comparisons. Journal of Semantics, 27(2):207-42, 2010b.

Jon Parwise and John Perry. Situations and Attitudes. MIT Press, Cambridge, MA, 1983.

Paul M. Pietroski. Events and Semantic Architecture. Oxford UP, Oxford, 2005.

Ivan A. Sag. Deletion and Logical Form. PhD thesis, MIT, 1976.

Uli Sauerland. Scalar implicatures in complex sentences. Linguistics and Philosophy, 27:367-391, 2004.

Barry Schein. Plurals and Events. MIT Press, Cambridge, MA, 1993.

Lenhart K. Schubert and Francis Jeffry Pelletier. Generically speaking, or, using discourse representation theory to interpret generics. In Gennaro Chierchia, Barbara H. Partee, and Raymond Turner, editors, Properties, Types, and Meaning, Vol. II, pages 193-268. Kluwer Academic Publishers, Dordrecht, 1989.

Roger Schwarzschild. Pluralities. Kluwer, Dordrecht, 1996. 
Mandy Simons. Dividing things up: The semantics of or and the modal/or interaction. Natural Language Semantics, 13(3):271-316, 2005.

Alice ter Meulen. Generic information, conditional contexts, and constraints. In E. Traugott, A. ter Meulen, J. Snitzer-Reilly, and C. Ferguson, editors, On Conditionals, pages 123-145. Cambridge UP, Cambridge, UK, 1986.

Kai von Fintel. Bare plurals, bare conditionals, and only. Journal of Semantics, 14(1):1-56, 1997.

Karina Wilkinson. Studies in the Semantics of Generic Noun Phrases. PhD thesis, University of Massachusetts, Amherst, 1991.

Yoad Winter. Distributivity and dependency. Natural Language Semantics, 8 (4):27-69, 2000.

Thomas Ede Zimmerman. Free choice disjunction and epistemic possibility. Natural Language Semantics, 8(4):255-290, 2000. 